\title{
Rural-urban health disparities among older adults in South Africa
}

\begin{tabular}{|c|c|}
\hline \multicolumn{2}{|c|}{$\begin{array}{l}\text { Authors: } \\
\text { Karl Peltzer }{ }^{1,2} \text { (D) } \\
\text { Nancy Phaswana-Mafuya }{ }^{1} \text { (D) } \\
\text { Supa Pengpid }\end{array}$} \\
\hline \multicolumn{2}{|c|}{$\begin{array}{l}\text { Affiliations: } \\
{ }^{1} \text { Department of Research and } \\
\text { Innovation, North West } \\
\text { University, Potchefstroom, } \\
\text { South Africa }\end{array}$} \\
\hline \multicolumn{2}{|c|}{$\begin{array}{l}{ }^{2} \text { HIV/AIDS/STIs and TB (HAST) } \\
\text { Research Programme, Human } \\
\text { Sciences Research Council, } \\
\text { Pretoria, South Africa }\end{array}$} \\
\hline \multicolumn{2}{|c|}{$\begin{array}{l}{ }^{3} \text { ASEAN Institute for Health } \\
\text { Development, Mahidol } \\
\text { University, Nakhonpathom, } \\
\text { Thailand }\end{array}$} \\
\hline \multicolumn{2}{|c|}{$\begin{array}{l}\text { Corresponding author: } \\
\text { Karl Peltzer, } \\
\text { kpeltzer@hsrc.ac.za }\end{array}$} \\
\hline \multicolumn{2}{|c|}{$\begin{array}{l}\text { Dates: } \\
\text { Received: } 18 \text { July } 2018 \\
\text { Accepted: } 19 \text { Feb. } 2019 \\
\text { Published: } 19 \text { June } 2019\end{array}$} \\
\hline \multicolumn{2}{|c|}{$\begin{array}{l}\text { How to cite this article: } \\
\text { Peltzer K, Phaswana- } \\
\text { Mafuya N, Pengpid S. } \\
\text { Rural-urban health } \\
\text { disparities among older } \\
\text { adults in South Africa. Afr J } \\
\text { Prm Health Care Fam Med. } \\
\text { 2019;11(1), a1890. https:// } \\
\text { doi.org/10.4102/phcfm. } \\
\text { v11i1.1890 }\end{array}$} \\
\hline \multicolumn{2}{|c|}{$\begin{array}{l}\text { Copyright: } \\
\text { C 2019. The Authors. } \\
\text { Licensee: AOSIS. This work } \\
\text { is licensed under the } \\
\text { Creative Commons } \\
\text { Attribution License. }\end{array}$} \\
\hline \multicolumn{2}{|l|}{ Read online: } \\
\hline 回回: & $\begin{array}{l}\text { Scan this QR } \\
\text { code with your } \\
\text { smart phone or } \\
\text { mobile device } \\
\text { to read online. }\end{array}$ \\
\hline
\end{tabular}

Background: There are limited studies assessing rural-urban disparities among older adults in Africa including South Africa.

Aim: This study explores rural-urban health disparities among older adults in a populationbased survey in South Africa.

Setting: Data for this study emanated from the 2008 study on 'Global Ageing and Adult Health (SAGE) wave 1' $(N=3280)$ aged 50 years or older in South Africa.

Methods: Associations between exposure variables and outcome variables (health status variables and chronic conditions) were examined through bivariate analyses and multivariable logistic regression.

Results: Rural dwellers were more likely to be older, black African and had lower education and wealth than urban dwellers. Rural and urban dwellers reported a similar prevalence of self-rated health status, quality of life, severe functional disability, arthritis, asthma, lung disease, hypertension, obesity, underweight, stroke and/or angina, low vision, depression, anxiety and nocturnal sleep problems. Adjusting for socio-demographic and health risk behaviour variables, urban dwellers had a higher prevalence of diabetes (OR: 2.36, 95\% CI: 1.37, 4.04), edentulism (OR: 2.79, 95\% CI: 1.27, 6.09) and cognitive functioning (OR: 1.91, $95 \%$ CI: $1.27,2.85)$ than rural dwellers.

Conclusion: There are some rural-urban health disparities in South Africa, that is, urban dwellers had a higher prevalence of diabetes, edentulism and cognitive functioning than rural ones. Understanding these rural-urban health variations may help in developing better strategies to improve health across geolocality in South Africa.

Keywords: rural-urban; health status; chronic conditions; disparities; older adults; South Africa.

\section{Introduction}

Noncommunicable diseases (NCDs) have become one of the world's biggest public health problems, contributing to premature death, disability, productivity losses and high health care costs that may eventually affect the achievement of the sustainable development goals. ${ }^{1}$ Ageing is often associated with decline in health status characterised by limited physical functioning, increase in chronic diseases as well as decrease in cognitive functioning. ${ }^{2,3}$ Social determinants of NCDs include socio-economic factors (e.g. poverty, inequality, rural-urban differences) ${ }^{4}$ and risky health behavioural repertoire that may have developed in earlier years (e.g. such as smoking, alcohol abuse, limited physical activity and unhealthy diet with high cholesterol, salt and saturated fats lacking fresh fruits and vegetables)., ${ }^{2,3,4}$

In many parts of the world, rural-urban health disparities persist in terms of socio-demographics, health care access, health status and prevalence of chronic conditions. Concerning sociodemographics, rural subjects were significantly younger, more likely to be women, widowed as well as have lower education and income than their urban counterparts in China. ${ }^{5}$ Similarly, older rural adults had significantly lower educational levels and less adequate income than older urban ones. ${ }^{6}$ Compared to single individuals, widowed middle and older aged South Africans living in urban communities were more likely to have hypertension and diabetes. ${ }^{7}$ Urban residence was found to be associated with better access to health care (hospital admission, private transport to a health facility, shorter travel distance to a health facility, private outpatient care, less often experienced catastrophic health care costs and utilisation of higher level public facilities) in South Africa. ${ }^{8}$ 
Regarding health status, rural older dwellers, including in South Africa, reported significantly lower overall health status and lower quality of life than urban ones.5,6,9 Among older adults in China, urban and urban-to-urban residents had the highest level of cognitive function, while rural and rural-to-rural residents had the poorest cognitive function. ${ }^{10}$ In Japan, the prevalence of cognitive impairment was higher in rural than urban areas. ${ }^{11}$ Rural residence in China was found to have higher functional limitation than urban residence, ${ }^{12}$ while in Bangladesh, urban dwellers reported more difficulties with activities of daily living or functional disability than rural dwellers. ${ }^{13}$ The prevalence of sarcopenia was significantly higher in rural elders than in urban elders in China. ${ }^{14}$

Among older adults, urban residence has been found to be associated with a higher prevalence of asthma morbidity, ${ }^{15}$ chronic lung disease, ${ }^{16}$ stroke, ${ }^{17}$ angina, ${ }^{16}$ hypertension ${ }^{16,17}$ and diabetes. ${ }^{7,15,16,18}$ Several studies found a higher prevalence of underweight or malnutrished among rural people rather than urban older adults. ${ }^{6,19}$ Being overweight or obese was found to be higher among urban than rural residents in Iran ${ }^{19}$ and South Africa, ${ }^{7}$ while in the USA, obesity was markedly higher among adults from rural versus urban areas. ${ }^{20}$ As a marker of oral health, edentulism was more prevalent in urban than rural older adults in Ghana. ${ }^{21}$

In terms of mental health, urban residence was associated with a higher prevalence of depression in China, ${ }^{16}$ while in other studies in China, rural subjects had a significantly higher proportion of depressive symptomatology than urban dwellers. ${ }^{5,22}$ Regarding health risk behaviours for NCDs, for example, the prevalence of alcohol use was significantly higher in the urban than rural areas in South Africa, ${ }^{7,18}$ vigorous physical activity was more prevalent among rural than urban dwellers in South Africa ${ }^{23}$ and tobacco use was significantly higher in the rural than urban areas in India. ${ }^{24}$ Compared to their rural counterparts, urban youth in South Africa were more likely to smoke and be physically inactive. ${ }^{25}$

There is a dearth of studies examining rural-urban differences in health at older ages on the African continent, including South Africa. ${ }^{18}$ This study examines rural-urban differences among older South Africans who participated in the Study of Global Ageing and Adults Health (SAGE). This study provides critical evidence for health policy planning for South Africa, the fastest ageing country in the African continent.

This study provides a general picture of rural-urban health disparities in relation to health status and chronic conditions.

\section{Research methods and design Sample and procedure}

This article utilised cross-sectional data from SAGE, a population-based study that had a sample of 3840 older
South Africans aged 50+ years. A two-stage probability sample was used and it produced representative estimates nationally and provincially by geographic type (urban and rural) and population group (black, mixed race, Indian or Asian and white); more details are discussed in Kowal et al. ${ }^{26}$ A good response rate (77\%) was obtained.

\section{Measurements and tools}

Socio-demographic variables assessed were: age, gender, educational level in years, geolocation, population or racial group and economic or wealth status.

The other complete measurements have been described previously, ${ }^{27}$ and are therefore only listed here: Economic or wealth status in wealth quintiles, Health risk behaviours (daily tobacco use, problem drinking) ( $\geq 10$ drinks or week), physical inactivity $(<600$ metabolic equivalent minutes per week) and inadequate fruit and vegetable consumption ( $<5$ servings a day). Health status variables: poor self-reported health status (bad or very bad general health), weak grip strength $(<30 \mathrm{~kg}$ for men and $<20 \mathrm{~kg}$ for women), functional disability (according to the International Classification of Functioning, Disability and Health, $50 \%-100 \%$ were defined as severe or extreme functional disability, using the 12-item WHO Disability Assessment Schedule, version 2 [WHODAS-II], high cognitive functioning [a median score of 48 or more]) and quality of life (assessed with the eight-item 'World Health Organization Quality of Life' scale). Chronic conditions: arthritis (symptoms algorithm based); asthma (selfreported diagnosed and/or symptoms algorithm based); lung disease and depression (symptoms algorithm based according to the International Classification of Diseases' 10th revision diagnostic criteria for research for depressive episodes); obesity (standard height and weight measures, $30 \mathrm{~kg} / \mathrm{m}^{2}$ ); diabetes, stroke, angina and edentulism (selfreported diagnoses); anxiety, sleeping problems (selfreported); measured hypertension (based on three averaged blood pressure measurements and/or taking antihypertensive medication) and measured low vision using a tumbling 'E' LogMAR chart. ${ }^{27}$

\section{Data analysis}

STATA software version 13.0 (Stata Corporation, College Station, TX, United States [US]) was used to analyse data taking the sampling design into consideration. Differences in proportions and means of exposure variables were tested using Chi-square and $t$-tests. Odds ratios (OR) were used to determine associations between exposure (sociodemographics and health risk behaviours) and outcome (health status and chronic conditions)variables using multivariate logistic regression. Weighted percentages have been presented in the tables. The $p$-value $(<5 \%)$ and $95 \%$ confidence intervals were used to indicate statistical significance taking the complex sample design into account. 
TABLE 1: Exposure variables by rural-urban residence $(N=3840)$.

\begin{tabular}{|c|c|c|c|c|c|c|c|c|c|}
\hline \multirow[t]{2}{*}{ Variable } & \multicolumn{4}{|c|}{ Rural $\dagger$} & \multicolumn{4}{|c|}{ Urbant } & \multirow[t]{2}{*}{$p$} \\
\hline & $M$ & SD & $n$ & $\%$ & $M$ & SD & $n$ & $\%$ & \\
\hline Age & 63.6 & 10.2 & - & - & 62.3 & 9.4 & - & - & $<0.001$ \\
\hline \multicolumn{10}{|l|}{ Sex } \\
\hline Female & - & - & 715 & 57.1 & - & - & 1485 & 55.2 & 0.404 \\
\hline Male & - & - & 561 & 42.9 & - & - & 1076 & 44.8 & \\
\hline Population group & - & - & & & - & & & & \\
\hline Black African & - & - & 920 & 90.8 & - & - & 1131 & 64.8 & 0.003 \\
\hline White African & - & - & 51 & 4.0 & - & - & 218 & 12.2 & \\
\hline Mixed race & - & - & 110 & 3.8 & - & - & 545 & 17.8 & \\
\hline Indian or Asian African & - & - & 22 & 1.5 & - & - & 285 & 5.1 & \\
\hline \multicolumn{10}{|l|}{ Education } \\
\hline$<7$ years & - & - & 785 & 70.7 & - & - & 901 & 41.3 & $<0.001$ \\
\hline $8-11$ years & - & - & 205 & 21.5 & - & - & 846 & 38.2 & \\
\hline 12 years or more & - & - & 76 & 7.7 & - & - & 339 & 20.5 & \\
\hline Low & - & - & 722 & 58.8 & - & - & - & 30.7 & $<0.001$ \\
\hline Medium & - & - & 250 & 19.7 & - & - & - & 17.4 & \\
\hline High & - & - & 299 & 21.5 & - & - & - & 51.8 & \\
\hline \multicolumn{10}{|l|}{ Marital status } \\
\hline Not married, single, widowed & - & - & 129 & 13.0 & - & - & 383 & 15.0 & 0.666 \\
\hline Married, cohabiting & - & - & 1115 & 87.0 & - & - & 2139 & 85.0 & \\
\hline Daily tobacco use & - & - & 285 & 21.7 & & - & 523 & 19.7 & 0.602 \\
\hline Problem drinking & - & - & 47 & 3.1 & - & - & 111 & 4.1 & 0.414 \\
\hline Physical inactivity & - & - & 780 & 58.1 & - & - & 1673 & 61.8 & 0.674 \\
\hline Inadequate fruit and vegetable consumption & - & - & 1048 & 75.1 & - & - & 1782 & 64.9 & 0.268 \\
\hline
\end{tabular}

$\dagger, n=1276$.

$\pm n=2561$

\section{Ethical considerations}

All essential study approvals were secured, that is, the Human Sciences Research Council (HSRC), Research Ethics Committee (Protocol REC 5/13/04/06) and the National Department of Health. Participants also provided voluntary written informed consent prior to participating in the study.

\section{Results}

\section{Sample characeristics}

The study sample had 3280 individuals aged 50 years or older ( $44.1 \%$ men and $55.9 \%$ women). The sample consisted of black Africans (74.0\%), followed by mixed race $(12.8 \%)$, white people (9.3\%) and Indian or Asian people (3.8\%). Rural dwellers were a little older and had a higher proportion of black Africans than urban dwellers. Urban dwellers had a higher formal education and were wealthier than rural dwellers. However, no rural-urban differences were observed in terms of sex, marital status, tobacco use, problem drinking, physical inactivity and inadequate fruit and vegetable consumption (see Table 1).

\section{Health status and chronic conditions}

Table 2 describes health status, physical chronic and poor mental health conditions by rural-urban residence (see Table 2). In terms of health status, $22.3 \%$ rural older adults and $14.9 \%$ urban older adults reported poor self-rated health status. Regarding physical chronic conditions, 5.6\% rural
TABLE 2: Prevalence of health status and chronic conditions by rural-urban residence.

\begin{tabular}{|c|c|c|c|c|}
\hline \multirow[t]{2}{*}{ Variable } & \multicolumn{2}{|c|}{ Rural } & \multicolumn{2}{|c|}{ Urban } \\
\hline & $n$ & $\%$ & $n$ & $\%$ \\
\hline \multicolumn{5}{|l|}{ Health status } \\
\hline Poor self-rated health & 230 & 22.3 & 386 & 14.9 \\
\hline Quality of life (low) & 385 & 36.2 & 571 & 24.3 \\
\hline Grip strength (weak) & 242 & 28.0 & 537 & 28.4 \\
\hline Functional disability (severe) & 142 & 14.6 & 223 & 9.2 \\
\hline Cognitive functioning (high) & 471 & 38.9 & 1322 & 58.9 \\
\hline \multicolumn{5}{|l|}{ Physical chronic conditions } \\
\hline Arthritis & 294 & 25.9 & 757 & 29.8 \\
\hline Asthma & 115 & 12.1 & 254 & 11.7 \\
\hline Lung disease & 86 & 6.4 & 153 & 6.4 \\
\hline Hypertension & 916 & 77.5 & 1923 & 77.2 \\
\hline Underweight & 65 & 5.8 & 120 & 4.1 \\
\hline Obesity & 445 & 42.5 & 1118 & 49.3 \\
\hline Diabetes & 62 & 5.6 & 297 & 11.1 \\
\hline Stroke and/or angina & 93 & 7.6 & 245 & 9.1 \\
\hline Edentulism & 44 & 3.5 & 324 & 11.1 \\
\hline Low vision & 502 & 43.4 & 1060 & 43.1 \\
\hline \multicolumn{5}{|l|}{ Mental health } \\
\hline Depression & 38 & 3.7 & 80 & 2.5 \\
\hline Anxiety & 119 & 11.5 & 171 & 8.5 \\
\hline Nocturnal sleep problem & 123 & 10.8 & 205 & 8.5 \\
\hline
\end{tabular}

and $11.1 \%$ urban older adults self-reported the diagnosis of diabetes. As regards to mental health, 3.7\% of rural and $2.5 \%$ of urban older adults were classified as having major depression.

Adjusting for socio-demographic factors and health risk behaviour variables, urban dwellers had a higher prevalence 
TABLE 3: Odds ratios for health status and chronic conditions by rural-urban residence.

\begin{tabular}{|c|c|c|c|c|}
\hline \multirow[t]{2}{*}{ Variable } & \multirow[t]{2}{*}{ Rural $\dagger$} & \multicolumn{2}{|c|}{ Urban } & \multirow[t]{2}{*}{$p$} \\
\hline & & OR & $95 \% \mathrm{Cl}$ & \\
\hline \multicolumn{5}{|l|}{ Health status } \\
\hline \multicolumn{5}{|c|}{ Poor self-rated health } \\
\hline Unadjusted & 1 (Reference) & 0.61 & $0.26,1.46$ & 0.260 \\
\hline Adjusted§ & 1 (Reference) & 0.77 & $0.38,1.55$ & 0.453 \\
\hline \multicolumn{5}{|c|}{ Quality of life (low) } \\
\hline Unadjusted & 1 (Reference) & 0.57 & $0.31,1.05$ & 0.068 \\
\hline Adjusted§ & 1 (Reference) & 0.78 & $0.44,1.39$ & 0.389 \\
\hline \multicolumn{5}{|c|}{ Grip strength (weak) } \\
\hline Unadjusted & 1 (Reference) & 1.02 & $0.62,1.69$ & 0.939 \\
\hline Adjusted§ & 1 (Reference) & 1.05 & $0.65,1.71$ & 0.831 \\
\hline \multicolumn{5}{|c|}{ Functional disability (severe) } \\
\hline Unadjusted & 1 (Reference) & 0.60 & $0.21,1.69$ & 0.322 \\
\hline Adjusted $\S$ & 1 (Reference) & 0.65 & $0.23,1.89$ & 0.423 \\
\hline \multicolumn{5}{|c|}{ Cognitive functioning (high) } \\
\hline Unadjusted & 1 (Reference) & 2.25 & $1.40,3.63$ & $<0.001$ \\
\hline Adjusted $\S$ & 1 (Reference) & 1.91 & $1.27,2.85$ & 0.002 \\
\hline \multicolumn{5}{|c|}{ Chronic conditions } \\
\hline \multicolumn{5}{|l|}{ Arthritis } \\
\hline Unadjusted & 1 (Reference) & 1.22 & $0.78,1.90$ & 0.381 \\
\hline Adjusted $\S$ & 1 (Reference) & 1.22 & $0.83,1.80$ & 0.302 \\
\hline \multicolumn{5}{|l|}{ Asthma } \\
\hline Unadjusted & 1 (Reference) & 0.96 & $0.62,1.49$ & 0.865 \\
\hline Adjusted $\S$ & 1 (Reference) & 0.97 & $0.70,1.44$ & 0.838 \\
\hline \multicolumn{5}{|l|}{ Lung disease } \\
\hline Unadjusted & 1 (Reference) & 1.00 & $0.51,1.95$ & 0.998 \\
\hline Adjusted $\S$ & 1 (Reference) & 1.01 & $0.56,1.82$ & 0.962 \\
\hline \multicolumn{5}{|l|}{ Hypertension } \\
\hline Unadjusted & 1 (Reference) & 0.98 & $0.59,1.64$ & 0.952 \\
\hline Adjusted§ & 1 (Reference) & 1.00 & $0.67,1.49$ & 0.995 \\
\hline \multicolumn{5}{|l|}{ Obesity } \\
\hline Unadjusted & 1 (Reference) & 1.31 & $0.83,2.09$ & 0.240 \\
\hline Adjusted§ & 1 (Reference) & 1.25 & $0.77,2.01$ & 0.353 \\
\hline \multicolumn{5}{|l|}{ Underweight } \\
\hline Unadjusted & 1 (Reference) & 0.82 & $0.49,1.37$ & 0.437 \\
\hline Adjusted§ & 1 (Reference) & 0.79 & $0.37,1.69$ & 0.537 \\
\hline \multicolumn{5}{|l|}{ Diabetes } \\
\hline Unadjusted & 1 (Reference) & 2.11 & $1.48,3.01$ & $<0.001$ \\
\hline Adjusted§ & 1 (Reference) & 2.36 & $1.37,4.04$ & 0.003 \\
\hline Stroke and/or & & & & \\
\hline Unadjusted & 1 (Reference) & 1.21 & $0.82,1.77$ & 0.324 \\
\hline Adjusted $\S$ & 1 (Reference) & 0.94 & $0.63,1.40$ & 0.743 \\
\hline Edentulism & & & & \\
\hline Unadjusted & 1 (Reference) & 3.43 & $1.50,7.87$ & 0.004 \\
\hline Adjusted $\S$ & 1 (Reference) & 2.79 & $1.27,6.09$ & 0.012 \\
\hline Low vision & & & & \\
\hline Unadjusted & 1 (Reference) & 0.99 & $0.61,1.61$ & 0.964 \\
\hline Adjusted $\S$ & 1 (Reference) & 0.86 & $0.55,1.35$ & 0.508 \\
\hline Depression & & & & \\
\hline Unadjusted & 1 (Reference) & 0.66 & $0.33,1.32$ & 0.233 \\
\hline Adjusted§ & 1 (Reference) & 0.73 & $0.33,1.64$ & 0.436 \\
\hline Anxiety & & & & \\
\hline Unadjusted & 1 (Reference) & 0.73 & $0.35,1.55$ & 0.406 \\
\hline Adjusted§ & 1 (Reference) & 0.82 & $0.45,1.50$ & 0.516 \\
\hline Nocturnal slee & & & & \\
\hline Unadjusted & 1 (Reference) & 0.68 & $0.32,1.47$ & 0.317 \\
\hline Adjusted§ & 1 (Reference) & 0.82 & $0.44,1.55$ & 0.539 \\
\hline
\end{tabular}

$\mathrm{OR}$, odds ratio; $\mathrm{Cl}$, confidence interval.

$\dagger, n=2202$.

$t n=1638$

$\S$, Adjusted for age, sex, population group, education, wealth, tobacco use, alcohol use physical inactivity and fruit and vegetable consumption. of diabetes (OR: 2.36, CI: 1.37, 4.04), edentulism (OR: 2.79, CI: 1.27, 6.09) and cognitive functioning (OR: 1.91, CI: 1.27, 2.85) than rural dwellers. No significant rural-urban differences were found on the other three health status measures (self-rated health status, quality of life and severe functional disability) and other chronic conditions (arthritis, asthma, lung disease, hypertension, obesity, underweight, stroke and/or angina, low vision, depression, anxiety and nocturnal sleep problems) (see Table 3).

\section{Discussion}

This study examined rural-urban health disparities among older adults in a national sample in South Africa. Rural older adults in this study were predominantly black African $(90.8 \%)$, while urban ones were proportionally more white and mixed race $(30 \%)$. As found in previous studies in developing countries, such as China, ${ }^{5,6}$ rural older adults in this study had less education and were less wealthy than urban older adults were. This could mean that rural older adults have less access to health care services than urban dwellers, and health care access should be improved for rural older adults in South Africa. ${ }^{8}$

Regarding health status, this study found that poor self-rated health and low quality of life were higher among rural than urban older adults, but this was not significantly higher. Previous studies have found that rural subjects reported significant lower overall health status and lower quality of life than urban dwellers. ${ }^{5,6,28}$ Poorer perceived health status and lower quality of life in rural dwellers may be related to lower socio-economic status and higher unemployment, which, in turn, reduce affordability of good nutrition and access to health care. ${ }^{9}$ This highlights the importance of an integrated national development plan in which the provision of health is not in isolation but situated within a larger developmental context.

Functional disability was in this study also higher among rural than urban older adults, but also not significantly. Previous studies found mixed results regarding the geographic determinants of functional disability. ${ }^{12,13}$ Although previous studies ${ }^{14}$ found a relationship between rural older adults and sarcopenia (or weak hand grip strength), this study did not find any rural-urban differences. Consistent with previous studies, ${ }^{10,11}$ this study found a higher cognitive functioning in urban compared to rural older adults. Better cognition in later life has been associated with higher levels of education..$^{29,30}$ Our urban sample had much more formal education than the rural sample, which may explain the higher levels of cognitive functioning among the urban older adults. It is possible that early and later life transitions of migration to urban areas, seeking and receiving higher levels of education, impacted on the levels of cognitive functioning in South Africa. ${ }^{10}$ Further studies should validate these findings and develop explanatory models that could help in describing the mechanisms responsible for the found associations. 
Regarding chronic conditions, urban residence was significantly associated with diabetes and edentulism in this study, as found in previous studies. ${ }^{15,16,21}$ The higher selfreported prevalence of diabetes in urban rather than rural areas may be related to a higher prevalence of combined risk factors, such as dietary changes, physical inactivity and obesity, ${ }^{16}$ and older adults in rural areas may have less access to being diagnosed with diabetes than in urban areas. ${ }^{16}$ Possible reasons for the higher prevalence of edentulism in urban areas may be related to dietary changes such as increased consumption of refined sugars, which may lead to caries and tooth loss, ${ }^{21}$ and dental care services and tooth extractions are more likely to be available in urban than rural areas. The study found that the prevalence of underweight was higher in rural than urban older adults, while the prevalence of obesity was higher among urban than rural older adults, but the differences did not reach significant levels. Previous studies ${ }^{6,19}$ confirm the relationship between rural residence and being underweight or malnutrition among older adults, while mixed results were found on urban-rural differences in relation to obesity.,19,20 The study found no rural-urban associations for arthritis, asthma, lung disease, low vision, stroke and/or angina and hypertension, while previous studies found an association between urban residence and asthma morbidity, ${ }^{15,16}$ chronic lung disease, ${ }^{16}$ stroke, ${ }^{16}$ angina ${ }^{16}$ and hypertension. ${ }^{16,17}$

Previous studies ${ }^{5,16,22}$ found mixed results regarding ruralurban differences and mental health indicators such as depression, while this study did not find significant differences for depression, anxiety and nocturnal sleep problems. Surprisingly, contrary to some previous studies, $7,23,24,25$ no rural-urban differences were found for behavioural risk factors of NCDs (tobacco use, problem drinking, physical inactivity and insufficient fruit and vegetable consumption). This could mean that health risk behaviours, such as tobacco use, problem drinking, physical inactivity and inadequate fruit and vegetable consumption, have penetrated into both urban and rural areas in South Africa. Therefore, health behaviour interventions should target rural and urban dwellers equally.

This study provides evidence that can be used to guide health care service provision in South Africa and elsewhere. The findings of this study (largely do not but sometimes do include rural-urban health disparities) should be contextualised given its limitations. Chronic conditions were subjectively reported, that is, based on self-reports or symptom algorithms. The cross-sectional nature of the design makes it difficult to determine causality. In conclusion, it is clear that few rural-urban variations exist in health status and chronic conditions. Understanding these rural-urban health disparities may help in developing better strategies to improve health in rural and urban areas.

\section{Acknowledgements}

The authors would like to thank the Department of Health, the United States National Institute on Aging and the Human
Sciences Research Council of South Africa for providing funding for this study.

\section{Competing interests}

The authors declare that they have no financial or personal relationships that may have inappropriately influenced them in writing this article.

\section{Authors' contributions}

All authors contributed towards data analysis, drafting and critically revising the article, gave final approval of the version to be published and agreed to be accountable for all aspects of the work.

\section{Funding information}

Funding was provided mainly by the National Department of Health, with further funding obtained from the United States National Institute on Aging through an interagency agreement with the World Health Organization and the Human Sciences Research Council, South Africa.

\section{Data availability statement}

Data sharing is not applicable to this article as no new data were created or analysed in this study.

\section{Disclaimer}

The views and opinions expressed in this article are those of the authors and do not necessarily reflect the official policy or position of any affiliated agency of the authors.

\section{References}

1. World Health Organization (WHO). Non-communicable diseases [homepage on the Internet]. [cited $2018 \mathrm{Jul}$ 17]. Available from: http://www.who.int/newsroom/fact-sheets/detail/noncommunicable-diseases.

2. World Health Organization (WHO). Global status report on noncommunicable diseases 2010. Geneva: World Health Organization; 2011.

3. Wu F, Guo Y, Chatterji S, et al. Common risk factors for chronic non-communicable diseases among older adults in China, Ghana, Mexico, India, Russia and South Africa: The study on global AGEing and adult health (SAGE) wave 1. BMC Public Health. 2015;15(1):88. https://doi.org/10.1186/s12889-015-1407-0

4. Niessen LW, Mohan D, Akuoku JK, et al. Tackling socioeconomic inequalities and non-communicable diseases in low-income and middle-income countries under the sustainable development agenda. Lancet. 2018;391(10134):2036-2046. https://doi.org/10.1016/S0140-6736(18)30482-3

5. Dong $X$, Simon MA. Health and aging in a Chinese population: Urban and rural disparities. Geriatr Gerontol Int. 2010;10(1):85-93. https://doi.org/10.1111/ j.1447-0594.2009.00563.x

6. Chen SH, Cheng HY, Chuang YH, Shao JH. Nutritional status and its health-related factors among older adults in rural and urban areas. J Adv Nurs. 2015;71(1):42-53. https://doi.org/10.1111/jan.12462

7. Egbujie BA, Igumbor EU, Puoane T. A cross-sectional study of socioeconomic status and cardiovascular disease risk among participants in the Prospective Urban Rural Epidemiological (PURE) study. S Afr Med J. 2016;106(9):900-906. https://doi.org/10.7196/SAMJ.2016.v106i9.10456

8. Harris B, Goudge J, Ataguba JE, et al. Inequities in access to health care in South Africa. J Public Health Policy. 2011;32(Suppl 1):S102-S123. https://doi.org/ 10.1057/jphp.2011.35

9. Van der Hoeven $M$, Kruger A, Greeff $M$. Differences in health care seeking behaviour between rural and urban communities in South Africa. Int $J$ Equity Health. 2012;11:31. https://doi.org/10.1186/1475-9276-11-31

10. Xu H, Dupre ME, Østbye T, Vorderstrasse AA, Wu B. Residential mobility and cognitive function among middle-aged and older adults in China. Res Aging. 2019;41(1):3-30. https://doi.org/10.1177/0164027518770780 
11. Nakamura K, Kitamura K, Watanabe $Y$, Shinoda H, Sato H, Someya T. Ruralurban differences in the prevalence of cognitive impairment in independent community-dwelling elderly residents of Ojiya city, Niigata Prefecture, Japan. Environ Health Prev Med. 2016;21(6):422-429. https://doi.org/10.1007/ s12199-016-0542-2

12. Zimmer $Z$, Wen $M$, Kaneda $T$. A multi-level analysis of urban/rural and socioeconomic differences in functional health status transition among older Chinese. Soc Sci Med. 2010;71(3):559-567. https://doi.org/10.1016/j. socscimed.2010.03.048

13. Kabir ZN, Tishelman C, Agüero-Torres H, Chowdhury AM, Winblad B, Höjer B. Gender and rural-urban differences in reported health status by older people in Bangladesh. Arch Gerontol Geriatr. 2003;37(1):77-91. https://doi.org/10.1016/ S0167-4943(03)00019-0

14. Gao L, Jiang J, Yang M, Hao Q, Luo L, Dong B. Prevalence of sarcopenia and associated factors in Chinese community-dwelling elderly: Comparison between rural and urban areas. J Am Med Dir Assoc. 2015;16(11):1003.e1-e6. https://doi.org/10.1016/ j.jamda.2015.07.020

15. Jie $Y$, Isa ZM, Jie X, Ju ZL, Ismail NH. Urban vs. rural factors that affect adult asthma. Rev Environ Contam Toxicol. 2013;226:33-63. https://doi.org/10.1007/978-1 4614-6898-1_2

16. Wu F, Guo Y, Kowal P, et al. Prevalence of major chronic conditions among older Chinese adults: The Study on Global AGEing and adult health (SAGE) wave 1. PLoS One. 2013;8(9):e74176. https://doi.org/10.1371/journal.pone.0074176. eCollection 2013

17. Duboz $P$, Touré $M$, Hane $F$, et al. Ageing and chronic diseases in Senegal. A comparison between rural (Ferlo) and urban (Dakar) populations. Bull Soc Patho Exot. 2015;108(1):25-31. https://doi.org/10.1007/s13149-014-0397-y

18. Oyebode O, Pape UJ, Laverty AA, Lee JT, Bhan N, Millett C. Rural, urban and migrant differences in non-communicable disease risk-factors in middle income countries: A cross-sectional study of WHO-SAGE data. PLoS One. 2015;10(4):e0122747. https://doi.org/10.1371/journal.pone.0122747. eCollection 2015

19. Iranagh JA, Motalebi SA, Chan YM, Iranagh NA, Iranagh EA, Rasouli J. Energy and macronutrient intakes in older urban and rural Iranian adults. Southeast Asian Trop Med Public Health. 2014;45(4):949-955.
20. Befort CA, Nazir N, Perri MG. Prevalence of obesity among adults from rural and urban areas of the United States: Findings from NHANES (2005-2008). I Rural Health. 2012;28(4):392-397. https://doi.org/10.1111/j.1748-0361.2012.00411.x

21. Hewlett SA, Calys-Tagoe BN, Yawson AE, et al. Prevalence and geographic distribution of edentulism among older Ghanaians. I Public Health Dent. 2015;75(1):74-83. https://doi.org/10.1111/jphd.12075

22. Li LW, Liu J, Xu H, Zhang Z. Understanding rural-urban differences in depressive symptoms among older adults in China. J Aging Health. 2016;28(2):341-62. https://doi.org/10.1177/0898264315591003

23. Pengpid S, Peltzer K, Phaswana-Mafuya N. Prevalence and correlates of physical activity among female and male adolescents and adults in South Africa. Gender Behav. 2018;16(1):11193-11206.

24. Chockalingam K, Vedhachalam C, Rangasamy S, et al. Prevalence of tobacco use in urban, semi urban and rural areas in and around Chennai City, India. PLoS One. 2013;8(10):e76005. https://doi.org/10.1371/journal.pone.0076005. eCollection 2013

25. Peer N, Bradshaw D, Laubscher R, Steyn N, Steyn K. Urban-rural and gender differences in tobacco and alcohol use, diet and physical activity among young . https://doi.org/10.3402/gha.v6i0.19216

26. Kowal $P$, Chatterji $S$, Naidoo N, et al. Data resource profile: The World Health Organization Study on global ÁGEing and adult health (SAGE). Int J Epidemiol. 2012;41(6):1639-1649. https://doi.org/10.1093/ije/dys210

27. Phaswana-Mafuya N, Peltzer K. Racial or ethnic health disparities among older adults in four population groups in South Africa. Ann Global Health. 2018;84(1):7-14. https://doi.org/10.29024/aogh.13

28. Baernholdt M, Yan G, Hinton I, Rose K, Mattos M. Quality of life in rural and urban adults 65 years and older: Findings from the National Health and Nutrition Examination survey. J Rural Health. 2012;28(4):339-347. https://doi.org/10.1111/ j.1748-0361.2011.00403.x

29. Andel R, Silverstein M, Kåreholt I. The role of midlife occupational complexity and leisure activity in late-life cognition. J Gerontol B Psychol Sci Soc Sci. 2015;70(2):314-321. https://doi.org/10.1093/geronb/gbu110

30. Deary IJ, Corley J, Gow AJ, et al. Age-associated cognitive decline. Br Med Bull. 2009;92:135-152. https://doi.org/10.1093/bmb/ldp033 